\title{
Editorial
}

\section{La Fiebre Manchada de las Montañas Rocosas en Costa Rica, una alerta al personal de salud.}

Las enfermedades infecciosas resultan de la interacción de al menos tres factores: el hospedero, el medio ambiente y el parásito (en su acepción puramente biológica). En el caso del hospedero, serán los mecanismos de defensa mecánicos como la piel y las mucosas, los innatos como la fiebre, la función NK y la fagocitosis entre otros y los adquiridos como la producción de anticuerpos específicos y la inmunidad dependiente de células, los que impedirán el ingreso, la multiplicación, la invasión y la expresión de los diversos mecanismos de virulencia de los agentes infecciosos. Los parásitos por su lado han desarrollado evolutivamente múltiples mecanismos de patogenicidad y virulencia que en su interacción con los hospederos, pueden producirles lesiones celulares y tisulares de diversa gravedad. El medio ambiente es importante en estas enfermedades, principalmente en las denominadas zoonosis, donde los microorganismos pueden ser transmitidos de animales infectados al ser humano ya sea directamente como en la rabia por la mordida de un animal infectado, al ponerse en contacto con materiales contaminados por animales infectados como en la leptospirosis o a través de insectos o artrópodos que se alimenta de sangre de animales infectados y pican a seres humanos susceptibles, como es el caso de las fiebres manchadas. La interrelación entre seres humanos, artrópodos o insectos transmisores y parásitos se lleva a cabo en nichos ecológicos con características bien definidas.

En el caso de las fiebres manchadas, la más frecuente en el hemisferios occidental es la fiebre manchada de las Montañas Rocosas, producida por Rickettsia rickettsii y transmitida por garrapatas de diversos géneros, capaces de parasitar múltiples animales domésticos y silvestres. ${ }^{1-3}$ Es muy interesante el comportamiento biológico de estos artrópodos; son parásitos hematófagos obligados de múltiples animales y se constituyen en algunos casos en transmisores y reservorios de agentes infecciosos como en la fiebre manchada de la Montañas Rocosas, la borreliosis o enfermedad de Lyme y las erhlichiosis. ${ }^{4}$ Se ha demostrado la transmisión transovárica así como entre los diversos estadios larvarios de la garrapata, de las rickettsias por lo que se considera como su principal reservorio en la naturaleza. ${ }^{4}$ Estos artrópodos son altamente resistentes a los cambios bruscos de las condiciones ambientales y pueden sobrevivir por largos periodos de tiempo sin ingerir alimentos pero en lugares oscuros, ya que son muy sensibles a la luz solar. En Costa Rica, diversos estudios han demostrado la presencia de garrapatas de los géneros Boophilus, Amblyomma e Ixodes en ganado bovino y Amblyomma, Ixodes Haemaphysalis y con menor frecuencia Boophilus y Anocentor en animales silvestres. En mascotas, principlmaente en perros, Rhipicephalus sanguineus y en segundo lugar las garrapatas del género Amblyomma son las más frecuentemente demostradas (Álvarez Víctor, comunicación personal) Todas estas garrapatas podrían ser vectores de esta y otras zoonosis.

Hasta el momento desconocemos estudios nacionales donde se analice la presencia de diversos agentes patógenos en estos artrópodos

En la revisión que aparece en este número sobre la fiebre manchada de la montañas rocosas, la Dra. L Hun analiza extensamente aspectos epidemiológicos, históricos, patogenéticos, clínicos y de diagnóstico de esta rickettsiosis haciendo énfasis en la experiencia que han obtenido en el laboratorio de la Virología de la Universidad de Costa Rica con esta zoonosis al haber investigado los diversos brotes en nuestro país, la mayoría localizados en las zonas norte y caribe. Llama la atención en la casuística presentada que de los 16 pacientes, fallecieron 10, con una letalidad del

ISSN 0001-6002/2008/50/2/75-76 Acta Médica Costarricense, (C2008 Colegio de Médicos y Cirujanos $62.5 \%$. Esto podría explicarse por un retraso en el diagnóstico, lo que ha sido observado en la literatura médica. ${ }^{1-3}$ Por ser una enfermedad poco frecuente, en general los médicos tienen una 
baja sospecha clínica, además, la triada de fiebre, exantema y antecedente de picadura de garrapata solo está presente en menos del $18 \%$ de los enfermos en la primera visita médica. ${ }^{3}$ El exantema clásico, tipo macular en tobillos, muñecas con extensión al tronco, palmas y plantas aparecerá entre los 3 y 5 días de enfermedad febril; en esta época más de $85 \%$ de los pacientes dan el dato de contacto previo con garrapatas. En los pacientes adultos, son usuales los síntomas inespecíficos al inicio, el exantema clásico es menos frecuente que en los niños, la historia de contacto con garrapatas es menos clara y la evolución es más grave ${ }^{1,2}$ El diagnóstico temprano y por lo tanto la terapia antibiótica adecuada con tetraciclinas, son los factores que incidirán en la mortalidad. ${ }^{1,3} \mathrm{Si}$ esto no sucede, la evolución fatal es la regla entre los 8 y 15 días de después del inicio de los síntomas. Se ha descrito también una evolución fulminante, con la muerte en los primeros cinco días de haber iniciado los síntomas. ${ }^{3}$

En general se ha establecido que Rickettsia rickettsii es una bacteria altamente virulenta, por lo que son infrecuentes los casos asintomáticos en humanos ${ }^{1}$, sin embargo, al menos en uno de los brotes analizados, en familiares de los pacientes se demostró seroconversión sin síntomas, lo que evidencia la necesidad de realizar más estudios seroepidemiológicos en Costa Rica.

Si bien el grado de virulencia de las cepas bacterianas podría explicar la alta letalidad observada en esta casuística, deben realizarse estudios al respecto.

La fiebre manchada de las montañas Rocosas es una zoonosis que ha sido diagnosticada en nuestro país en forma de brotes con una alta mortalidad probablemente por un diagnóstico tardío. En Costa Rica tenemos los artrópodos transmisores, las garrapatas ampliamente extendidas en el territorio y la posibilidad de que los seres humanos entremos en contacto con ellas, principalmente en estos tiempos en que el turismo ecológico y la tenencia de mascotas es tan frecuente en los hogares, por lo que el personal de salud debe estar atento ante la posibilidad de enfrentarse a esta enfermedad, sospechándola ante datos clínicos y epidemiológicos de alarma, con el fin de realizar un diagnóstico y tratamiento tempranos, lo que disminuiría la alta mortalidad demostrada en el presente estudio.

Son necesarios más estudios nacionales para dilucidar aspectos epidemiológicos y clínicos de esta rickettsiosis, así como investigaciones sobre el papel de las diversas especies de garrapatas en la transmisión de esta y otras zoonosis como la borreliosis y las erhlichiosis.

Agradecimiento: al Dr. Víctor Alvarez del Ministerio de Agricultura y Ganadería y al Dr. Luis Víquez Solano, médico veterinario.

\section{Ricardo Boza-Cordero \\ Servicio de Infectología \\ Hospital San Juan de Dios}

\section{Referencias:}

1. Walker DH Raoult D Rickettsia rickettsii and Other Spotted Fever Group Rickettsiae In Mandell, Bennett, \& Dolin: Principles and Practice of Infectious Diseases 6th edition 2005; 2287-2295

2. Walker DH Rickettsiae and Rickettsial Infections: The Current State of Knowledge Clin Infec Dis 2007;45:S39-S44

3. Thorner AR Walker D Petri WA Rocky Mountain Spotted Fever Clin Infect Dis 1998;27:1353-1360

4. Parola P Raoult P Ticks and Tickborne Bacterial Diseases in Humans: An Emerging Infectious Threat Clin Infect Dis 2001; 32:897-928 